\title{
INVESTIGATING THE FACTORS THAT AFFECT THE ADOPTION OF ORGANIC AGRICULTURE IN ASOKWA, KUMASI METROPOLIS
}

Frank Y. Adusei

Ministry of Food and Agriculture, Ghana.

\section{AR T I C L E I N F O}

\section{Article history}

Received: July 03, 2020

Revised: December 16, 2020

Accepted: December 21, 2020

\section{Keywords}

Organic agriculture

Urban agriculture

Adoption

Non-adoption

Vegetables
A B S T R A C T

Urban agriculture, particularly organic vegetable production is promoted because of its contribution to food security and enhanced income. More so, organic agriculture considerably enhances the income of urban farmers who practice it. The objective was to investigate the factors that affect farmers' decision to adopt organic agriculture. Due to the contamination of vegetables with conventional agriculture systems, increasing concerns about the quality of food, the health of consumers and the environmental impacts of farming systems, organic agriculture is being promoted by the Ministry of Food and Agriculture as a means of addressing the problem. Since the introduction of organic agriculture, some farmers have adopted the technology while others have not. Sixteen farmers were selected, ten from those adopting and six from those not adopting. Semi-structured in-depth interviews were used to extract data from the participants. For those who adopted, the knowledge of their parents and forefathers on agriculture and their personal experiences by comparing their organic produce with conventional ones greatly inspired their decision on adoption. Factors leading to non-adoption are: inadequate awareness about organic farming, difficulty in controlling pests, diseases and improving soil fertility and perceived lack of market for the organic vegetables. As a result, effective extension monitoring and training are recommended to enhance the adoption and sustainability of organic agriculture.

Corresponding Author: Frank Y. Adusei

Email: fyadusei@gmail.com

(C) The Author(s) 2020.

\section{INTRODUCTION}

It has been reported by Ravallion et al. (2007) that, about one-quarter of the poor people in developing economies live in urban areas. By the year 2050, the world population is expected to have swelled to 9.5 billion and approximately $66 \%$ of the world 's population will be living in the urban areas (UN 2014). Presently, the majority of the world population growth is in the cities, especially in developing countries. Urban areas worldwide are expected to absorb all the population growth expected over the next four decades and continue to draw in the rural population (United Nations
2018). This rapid urbanization, as claimed by Overman and Venables (2005), is often an inspiring development, as urban centres are expected to be productive as compared to rural areas hence, a driver of economic development and growth. The Resource Centres on Urban Agriculture and Food Security (RUAF, 2010) emphasizes that rapid urbanization often go together with increasing poverty and food insecurity resulting from increasing food prices, over dependence on imports and growing unemployment. For the purpose of this paper, the terms metropolitan and urban will be used interchangeably since the two mean the same. For 
urban household's, food represents a substantial component of the expenditure, especially poor households who spend about 60-80 percent of their earnings on food (Maxwell et al., 1998; Armar-Klemesu, 2000). Thus, the ability to obtain income forms a major component of ensuring household well-being since a substantial amount of food consumed in the urban areas must be purchased. Nevertheless, most of these households lack the purchasing power to acquire adequate food requirement. In rural areas there is relatively abundance of land which has favourable agroecological potential for growing different crops. With all these advantages people in rural areas should have been food secured but unfortunately, majority of them are not. They often lack access to secured land tenure and most of them are too poor to purchase enough food (FAO, 2006). The rural agriculture has been going through a process of land use changes resting mainly in the decreasing proportion of agricultural land and the process of diversification.

Urban agriculture (UA), however, has also gone through some changes over the years. In the years past, farmers harvest their produce and send it through marketers/distributors and supply networks to supermarkets, stores and general market places where urban consumers finally buy them without having any idea about the source of their food. But times have changed and the whole food system has undergone unprecedented changes. Consumers are more particular about what goes into the production of what they are consuming.

Feeding people in the years to come will involve great initiative and advance technology to produce more food on less available land in a more sustainable way. The growth in population, changing eating habits, water and land scarcity are also long-term trends that threaten a shared vision of a country`s prosperous future in which well-fed people are able to achieve their full potential without damaging their ecosystem. Researchers and farmers have been forced due to pressures to reassess the mainstream techniques in farming and to take into account another possibility of methodologies to procuring food which includes organic agriculture and intercropping.

Many people see UA as an engagement in food production and or related activities within or nearby metropolis, which is practised by several participants with different intents or motivations and backgrounds
(Duží et al., 2014; Simon-Rojo et al., 2016). The scope is from small-scale food self-sufficient, usually called urban gardening which is practiced by an individuals or small group of farmers to a large-scale UA. To distinguish between diverse types of farms and gardens, several typologies have been proposed. Urban agriculture spans all communities, places, actors and economies which is focused on primary production in the cities or metropolitan areas categorized as urban (Cabral et al., 2015). The UA can conveniently be classed into two subgroups; urban food gardening (backyard) and urban farming (intensive production). The common denominator of both is the output of products, whether it is harvested and consumed in the case of backyard gardening or sold to urban dwellers as with intensive production. In this report, UA represent intensive production of vegetables in the metropolis.

Metropolitan agriculture serves different purposes concurrently. For example, the growing of rice in the floodplains in Antananarivo, Madagascar provides a staple crop for a large segment of the urban populace thereby contributing to food security. It also mitigates floods in the raining season; contributes to income generation; job creating for farmers and their workers and other actors along the value chain; and reuse of urban wastewater (Renting et al., 2013). Rooftop farming also contributes to the greening of the cities, reduce energy consumption for heating and cooling buildings and generate biodiversity (Mandel, 2013; Ackerman et al., 2014).

Looking at UA neck and neck with rural agriculture, its input to the Gross Domestic Product (GDP) may be minimal but the importance for certain commodities especially vegetables might be significant particularly if we are to cogitate the whole value chain (Drechsel et al., 2007). Report by UN-Habitat has highlighted the significance of UA on how cities can work with nature. In these studies, it was contended that, to achieve environmental and economic resilience, biodiversity needs to be restored in urbanized areas (UN Habitat, 2012). One major benefit of UA lies in its contribution to the urban environment, green infrastructure and the related ecosystem services (Golden and Hoghooghi, 2017; McEldowney, 2017; Santo, 2016; Samson et al., 2017; Piorr et al., 2018).

Urban agriculture can make positive impacts to food and nutrition security (Eigenbrod and Gruda, 2014; Poulsen et al., 2015). Nevertheless, availability of land within and 
around metropolitan areas is often a constraint (Badami and Ramankutty, 2015). However, between 100 and 800 million people are projected to earn part of their income directly from UA or to be intensely involved in it for sustenance globally. Drechsel and Keraita (2014) estimated that, $60 \%$ of urban dwellers in Accra, Ghana can be full or part time urban farmers. Numerous studies have shown that urban farmers in Sub-Saharan Africa earns significant incomes higher than the minimum subsistence income. This imply that UA contributes meaningfully to economic development (Poulsen et al., 2015).

For some time now organic agriculture (hereafter referred to as $\mathrm{OA}$ ) is gaining popularity due to promotion by some organisations including international development agencies, governmental and non-governmental bodies. These bodies see OA as a propoor strategy for improving agricultural output and the livelihood conditions of farming households in SSA (Mamuya, 2011). They contend that management of organic agriculture practices can help address poor soil condition and rigorously degraded soils (UNEPUNCTAD, 2008). The concept of exploiting our resources and technology in producing enough to feed the everincreasing human population would have been a laudable one but for the long-term negative effects of some of those technologies on the soil and environment. The cost of inorganic fertilizers is relatively high besides, constant use for production makes the soil acidic. It is also a threat to human health and aquatic life when washed into water bodies.

In the beginning agriculture was done organically. Many years has passed by, since humans started farming without using artificial or inorganic fertilizers but relying on organic fertilizers obtained from plants and animals. These organic products protect animals and crops from pests and diseases using naturally occurring materials (Kristiansen, 2003). In 1842, Lawes started the first factory for the production of artificial fertilizers in the UK and in 1843, he together with Gilbert (chemist), began the first long-term field experiments to measure the effect on crop yields of inorganic and organic fertilizers. Together, they brought to light the elements of modern agriculture and founded the crop nutrition principles. Throughout the following century, farmers around the world successfully developed farming systems that relied progressively on artificial or inorganic fertilizers. Nonetheless, during the past two decades or more the situation has begun to change. Increasing concerns about quality of food, health of farmers and the environmental impacts of farming systems, for example, have focused the attention of researchers, policy makers, consumers and farmers on alternative productions systems, including organics (Ibid.).

Urban agriculture is connected with health and environmental risks. Firstly, when UA is not conducted according to the best practices may infect the urban environment through agrochemical deposits or excess nitrate in water routes and water supplies. Secondly, it can be impacted by containments emitted by other urban activities, that is by uptake of heavy metals in soils, water or air pollution. Last of all, UA is also associated with occupational health risks through agrochemical management and possible conflict with non-farming neighbours (de Zeeuw, 2004). Largely, due to the contamination of vegetables with conventional agriculture systems, increasing concerns about the quality of food, the health of consumers and the environmental impacts of farming systems, organic agriculture is being promoted by the Ministry of Food and Agriculture as a means of addressing these menaces.

\section{Objective of the study}

This study aims to empirically analyse the degree of Metropolitan agriculture in Asokwa. Specifically, the study assesses the rate of participation of Metropolitan agriculture in Asokwa and to investigate the factors that influence the farmers decision to adopt organic agriculture.

\section{LITERATURE REVIEW}

\section{Delineation of Metropolitan agriculture}

Urban agriculture has been defined by several authorities with different concepts. As a result, there has been many emphases in definitions. However, the researcher did not attempt to define but to come out with common concepts in the definition:

\section{a. Types of economic activities:}

This refers to the production aspect of agriculture. Some delineations add trade and processing to production and emphasise on relations between them. As well as being wide-ranging, analysis of the commodity offers an integrated approach which is 
mostly pertinent to UA. Due to larger geographic proximity and faster resource flow, production, trade and processing tend to be more inter-related in time and space than agriculture in rural areas.

\section{b. Food/non-food categories and sub-categories:}

Some definitions tend to highpoint varied agricultural systems, where more food productions fit for consumption by humans and or livestock. This may either be planted or raised food products including grain, vegetable, root, fruit crops, aromatic and medicinal herbs and livestock of all type. Definitions basically put more light on perishable and comparatively high-valued vegetable, animal products and by-products. Many researchers take into account, food productions solely, while others include both food and non-food productions. As such, systems are often communally complementary, regularly gendered and strengthen not only food security but also economic and environmental benefits at various levels that is from individual to metropolis.

\section{c. Intra-urban/peri-urban character of location:}

So far, the common component in most definition is the issue of location that is: within and around cities or metropolitan areas (Ganapathi, 1983; Sawio, 1993; Smit et al., 1996). Perhaps, location is the key source of debate. Largely, UA studies have been accomplished in national capitals or metropolitan areas. However, few actually distinguish between intra and peri-urban settings. But those who do so have used it as criteria, for intra-urban agriculture, density thresholds, population sizes, authorized city limits(Gumbo and Ndiripo, 1996; Murray, 1997) metropolitan boundaries of the town, agricultural use of the land zoned for other purpose (Maxwell et al., 1998; Mbiba, 1994). Research by CIRADAgricongo (open-space) market vegetable farming in Brazzaville for instance, gardens within the city limit are considered "intra-urban" whiles those off-limit (though within a certain travel-time band are called "peri-urban" (Moustier, 1999).

\section{d. Areas where UA is practiced:}

Using area as a criterion, authors have a divergent view which includes: location related to place of residence (off-plot or on-plot), development status of site (open-space or built-up), modality of tenure (sharing, lease, authorized or unauthorized through personal agreement, commercial transaction or customary law); the official land-use category of the sector where UA is practiced (institutional, industrial residential). Some studies have focussed on backyard areas (Lee-Smith, 1957; Regis, 1999) and others have also targeted their study at open space locations (Mbiba, 1994; Freeman, 1991; Dennery, 1996).

\section{e. Product destinations:}

Most definitions include agricultural production for both trade (sale, barter, gifts) and home consumption. Both focuses are usually found to be targeted to differing degrees by the producers. Research has been aimed at specific (export) market-oriented productions and has helped to better understand the economic performance of UA, its comparative advantages over other supply sources, both at the producer and consumer level. On the home consumption level, relatively more attention must be paid to the economics of animal assets and the exchangeability of supplemental food home consumption afforded by UA to households. (Gonzales, 1999).

\section{f. Production systems (scale of):}

Some definitions ignore others embrace specific types of production systems. Usually, the focus is on individual, family micro, small and medium enterprises, as opposed to large, national or transnational enterprises. Nevertheless, current studies show that the bigger interact in more than one way with smaller market-oriented units, often even to the expense of units primarily geared to home consumption (peri-urban areas). For some time in UA corporate out-sourcing has been practiced, predominantly in the cities of Asia, however, trade liberalization is also making it appealing in a growing number of productions in cities especially in Africa and Latin America.

\section{Ideologies of organic agriculture}

Organic agriculture is no longer just a phenomenon of industrialized countries. It is now commercially operated in more than 120 countries, representing about 31 million ha of certified cropland and pasture with a 
market share of US $\$ 40$ billion in 2006 (Willer and Lernoud, 2019). The production is evaluated to be growing at $30 \%$ a year globally in response to market request. The demand for certified organic products, especially vegetables, currently exceeds supply and in many cases, produce attracts some premium prices (Ashely et al., 2007). Study conducted by Smukler et al. (2008) reveals that organic agriculture is experiencing a rapid change as the demand for healthier food and more environmentally sound production increases globally. Large producers are adopting organic production to meet this growing demand. The significant internationally accepted standards which consists of multitude of rules on how to cultivate, control weed, disease, pest and animal husbandry have already been set out in IFOAM. Organic agriculture is governed by rules and principles just as any other farming. This sweeping statement has been established by the International Federation of Organic Agriculture Movements (IFOAM). Organic agriculture is particularly an environmentally friendly type of farming that seeks to run the farm as an integrated system (Mader, 2002; Best, 2010). The OA approach is based on the principles of care, health, ecology and fairness.

The principle of health means that OA should sustain and enhance the health of plant, soil, animal and human as one and inseparable whole;

The principle of ecology means that, OA should be based on living ecological systems and cycles, work with them and help sustain them. Food production is itself a component of the local ecology. The more in tune the production process is with that ecology, the smaller the chance of difficulties arising;

The principle of fairness refers to, this principle recognizes human and social issues as well as environmental concerns. This relationship is to be developed to ensure fairness and respect to life opportunities and common environmental issues.

The principle of care recognizes that agriculture should be managed in a responsible way to protect the health and well-being of current and future generations and the environment.

\section{Organic Agriculture Defined}

According to Food and Agriculture Organization (2005), $\mathrm{OA}$ is defined as 'a holistic production management system which promotes and enhances agro-ecosystem health, including biodiversity, biological cycles and soil biological activity. To achieve this, agronomic, biological and mechanical approaches are to be observed instead of using synthetic substances. According to IFOAM (2004), genetically modified organism (GMO) does not in any way form part of OA. The above definition is pregnant with several approaches that enhances agroecosystem health which are:

- crop rotation, which ensures that one crop or crops from the same family does not follow each other to deplete the soil of the nutrients that it needs most;

- cover crops to protect against all forms of soil erosion;

- the growing of special crops called "green manures" that are ploughed back into the soil to enrich it.

- 4the addition of plant wastes and aged animal manures, also known as compost, to the soil.

\section{METHODOLOGY}

\section{Study area}

The Asokwa Municipal was created by a Legislative Instrument 2294, 2018 by an Act of Parliament on the $21^{\text {st }}$ December, 2017 under section 3 of the Local Government Act 2016 (Act 936). The Municipality is one of forty-three (43) Districts / Municipals / metropolitans in the Ashanti Region. The municipal is the centre of the region and it is located between Latitude $6.35^{\circ} \mathrm{N}$ and $6.40^{\circ} \mathrm{S}$ and Longitude $1.30^{\circ} \mathrm{W}$ and $1.35^{\circ} \mathrm{E}$, elevated 250 to 300 metres above sea level. The Municipal shares boundaries with Subin to the North, Bosomtwe to the south, Oforikrom to the east and Nhyiaeso to the west. It covers an estimated land area of $23.04 \mathrm{~km}$ square which is approximately 0.094 percent of the Ashanti regions land area $(24,389 \mathrm{~km}$ square). Ghana recorded a population of $24,658,823$ in the 2010 Population and Housing Census compared to $18,912,079$ in 2000, Ashanti Region recorded a population of 4,780,380 in 2010 compared to 3,612,950 in 2000 and Asokwa Municipality recorded a population of 140,161 (2010). The Municipality has an intercensal growth rate of $2.7 \%$. There is currently a high competition for land for commercial, residential and agriculture activities. The agriculture in the Municipality focuses on the cultivation of vegetables such as carrot, cabbage, lettuce, spring onion, raddish and beet root as well as rearing of livestock such as cattle, pigs, goat, sheep, poultry and 
aquaculture. Gyinyase, Atonsu and Ramseyer are the major vegetable production site in the municipality and probably one of the highest in the region (Asokwa Municipal Assembly, 2019). There are three farmerbased organisations (FBOs) out of which two have registered with Registrar General of Ghana. The FBOs are Farmwell at Gyinyase (registered), Peace and Love at Atonsu (registered) and Progressive at Ramseyer (not registered).

Table 1. Narrative of farmers and key informant (MoFA).

\begin{tabular}{lccccccc}
\hline & \multicolumn{7}{c}{ Those adopting } \\
\cline { 2 - 8 } Site of farm & Female & Male & Total & Female & Male & Total & Key informant \\
\hline Atonsu & 2 & 4 & 6 & 1 & 3 & 4 & 2 \\
Gyinyase & 1 & 2 & 3 & 1 & 1 & 2 & 0 \\
Ramseyer & 0 & 1 & 1 & 0 & 0 & 0 & 0 \\
Total & 7 & 3 & 10 & 2 & 4 & 6 & 2 \\
\hline
\end{tabular}

Source: Data from the field.

\section{Research Design}

The study used qualitative approach and employed a case study method by using semi-structured in-depth interview to collect data. To analyse, discuss and synthesize the empirical data collected with the existent literature, thematic analysis was used.

\section{Sampling}

Pre-testing of the questionnaire in the study area showed that a variety of people are involved in metropolitan agriculture. Farmers within the study area are known by the researcher since he is an Agricultural officer. Nevertheless, two Agricultural officers in the study areas provided a list of names for random selection of both groups of participants by the researcher. Some farmers were purposefully chosen from the merged list to meet the objective of the study including age, years of adoption of $\mathrm{OA}$, gender and the positions within the farmer group. The age factor was to consider the diversity of age group of those taking part which may have informed their decision. The year of adoption was to ensure that participants have a rich facts and figures on the issues at hand. Gender as a criterion was to help appreciate how the adoption of $\mathrm{OA}$ may be enhanced by both sexes. Leaders and ordinary members in the inclusion was to corroborate opinions.

\section{Data collection}

Data were collected from desk study and primary data. The desk study was to review relevant literature on the subject at hand from journals, reports, articles and internet. The primary data was collected through semistructured in-depth interview which took a form of open-ended questionnaires to further induce discussion. The interview was face-to-face with a respondent at a time to learn about their beliefs and ideas. Data was collected from two different classes of farmers: those applying the OA concept and non-adopters. Agricultural officers also formed part as key informants. To this effect, farmers applying the $\mathrm{OA}$ approaches have been approved by the Ministry of Food and Agriculture (MoFA) and they are been monitored.

\section{Semi-structured in-depth interviews}

In all 10 interviews were conducted with those adopting OA (7 males; 3 females) and 6 with those not adopting OA (4 males; 2 females). The purpose of this interview was to learn more about views of people, their

judgements and understand their experiences and perceptions on the topic at hand. Participant observation to various farms were done. Some of the challenges were weed and pest infestation and marketing aspects of both organic and conventional produce. The interviews were conducted in Twi, the native language in the study sites and were interpreted precisely to English. The Table 1 shows the number and description of farmers interviewed.

\section{Key informant interview}

Two key informant interviews were carried on gaining deeper insights into the factors affecting the adoption of organic agriculture in the study sites and to examine some of the issues raised by farmers. These comprised of two Agricultural officers from MoFA in the Asokwa Municipal. These interviews were conducted in English. 
All the interviews were recorded and transcribed manually.

\section{RESULTS FROM THE FIELD}

Interviews and analysis are done to extracts explanations or understanding from primary data collected. This reflects how the researcher makes meaning of specific experience by analysing the farmer's know-hows, approaches and views. The aim of the analysis is to examine the symbolic content and importance of the data collected. For clarity and simplicity in terms of results and analysis, the outcome was then discussed. Subsequently the empirical data collected was in the nature of descriptive and narrative, the analysis took the form of thematic enquiry.

\section{Decision for OA adoption}

The organic agriculture concept was made known to the farmers by Agricultural officers by means of trainings. Through trainings the farmers became conscious and acquired skills and knowledge of the possible adverse effects on human health and ecosystem. Out of 10 farmers who have adopted OA, 8 of them representing $80 \%$ pointed out that the knowledge of their parents and forefathers on agriculture greatly inspired their decision on adoption. They recalled to mind that their parents and forefathers lived long and healthy life by practicing and eating produce from OA. The other two farmers, representing 20\% responded that their adoption choice was influenced by their personal experiences by comparing their produce from agro-chemical field with those without synthetic chemicals. They realized that their produce without agro-chemicals had a longer shelf life and tasted better. Access to information and knowledge of OA invigorated them to adopt the knowhow as was affirmed by all the farmers who adopted. Last of all, most adopters denoted that supposed susceptibility to ill-health challenges, which may result from using agro-chemicals to grow their foods contributed to the reason why they adopted.

\section{Established Policies and Institutional Framework}

Policies relating to training and extension and marketing of organic products are established in character. This policy framework also influenced adoption of $\mathrm{OA}$ by farmers in this research. All of the adopted participants who were interviewed indicated that, at least they have participated in trainings that was organized by MoFA before and after practising $\mathrm{OA}$. Yet, only 3 participants openly said that the training and extension practical support influenced their decision to adopt it. The Ministry of Food and Agriculture (MoFA) is the main organisation and central point of the Government of Ghana, in charge of developing and implementing policies and strategies for the agricultural sector within the framework of a coordinated national socio-economic growth and development agenda (Ministry of Food and Agriculture, 2007). The Agricultural officers also mentioned that trainings are organized for the farmers every now and then. Besides, monitoring of farmers activities are been done almost every day. Participants acquired some practical skills and knowledge on organic agriculture techniques through the training and extension support and cultivated the belief that inspired them to start and remain using the know-how. All of the adopted participants noted that, access to extension services was one of the reasons they commenced OA. They also mentioned that the trainings made them convinced and became more dedicated. Currently, marketing of organic produce is a challenge as described by the participants but also, all of them indicated to the prospect of organic premium market access in the future as more people become aware of their health. Future market access for organic produce is one of the key motivating factors for adoption.

\section{Cultural heritage}

Eighty percent of the adopted farmers regarded OA as

the farming heritage that their parents and forefathers handed down to them. These farmers treasured and attributed a culture of healthy eating and good food with their parents and forefathers farming legacy. To them, this is also intrinsic in $\mathrm{OA}$ for the reason that its prohibition of synthetic agro-chemical inputs and its emphasis on healthy lifestyle. All the eight farmers who adopted $\mathrm{OA}$ sought not to only to reinforce the farming legacy of their parents and forefathers, but also to encourage the culture of healthy food and lifestyle, which they believe people should make every effort to live. They also viewed OA as low-cost technology for the fact that agro-chemicals use is absent and the money involved in buying and applying them is saved.

\section{Decision for not adopting $\mathrm{OA}$}

Out of six, three participants who did not adopt OA 
mentioned either inadequate awareness and or lack of knowledge about organic farming as a hindrance to adoption. This was linked to lack or inadequate extension officers who might have trained them about economic viability of organic agriculture. Two other participants cited that controlling pests, diseases and improving soil fertility would be much difficult with OA, hence their non-adoption. They concluded that when they realized that with $\mathrm{OA}$, farmers are not permitted to use agro-chemicals on their farms they understood it will be a challenge and physically drudgery work. Lastly, one farmer decided not to adopt due to perceived lack of market for the organic vegetables.

\section{DISCUSSIONS}

Organic vegetable production in the study sites give the idea of unique challenges. These consist of disease and pest prevalence, limited markets for organic outputs, a sizeable number of small-holder production often with limited access to technical means and reliance on domestic markets for selling produce. Although, the study took place in the metropolitan (urban) setting, each Farmer-based organization have their farm located or concentrated in the same neighborhood with comparable conditions. All the participants cited that their household is food secured due to improvement in livelihoods.

The Agricultural officers motivated the farmers that choices of food for the urban dwellers, especially the select few were changing from conventional to organic products. The financial drive influenced the decision of the adopters on making a high and profitable farm income through access to high priced paying markets for organic produce. The findings showed that providing farmers with information about the potential health effects of agro-chemicals (pesticides and herbicides), the knowledge of disease, pest and soil fertility management and the financial viability of organic agriculture can inspire further adoption.

As pointed out by the participants, mainly those not adopting OA, the essential training should be provided by Agricultural officers (MoFA). Particularly, trainings should consist of weed control, organic pest and disease, soil improvement, and concern about quality food and health. Again, training on how organic agriculture could raise farmers financial resources through improved productivity and profitability. These trainings may clear any doubt or obstacle preventing non-adoption of OA. Results also revealed that adoption decision-making was influenced by myriad of motives which are intertwined and conveniently grouped into: environmental conservation, food-safety and healthy lifestyle as well as market access.

Both the organic and conventional farmers were selling on the same markets attracting same prices for their produce. This is as a result of relatively low consumer awareness of $\mathrm{OA}$ and because the market for them is still underdeveloped and comparatively medium, regardless of its potential for growth. The researcher believes that there should be the need for increased consumer awareness creation about the advantages of consuming organic products. Adding little premium with regards to pricing of organic products would also encourage more farmers to adopt $\mathrm{OA}$ practices.

\section{CONCLUSIONS}

From the above discussions so far, it could be concluded that agro-chemical residues in vegetables has a disturbing impact on consumers since such food stuffs are mostly eaten fresh and raw. Organic products often contain lower pesticide and nitrate levels residues than conventionally-produced vegetables. Organic agriculture cannot guarantee that products are always completely free of synthetic agro-chemical residues due to general environmental pollution (FAO/WHO, 2005). It is possible that $\mathrm{OA}$ products are contaminated from highly persistent agro-chemicals in soil and water, or contamination through agro-chemical drift from adjacent conventional farms, even though drift can be minimized by planting hedgerows (Gonzalez et al., 2005). In spite of these restrictions, OA can help farmers meet increasingly strict vegetable production standards. It is of great importance that urban agriculture be integrated into urban planning to help link sustainable food provision and resource processes to infrastructural productive urban landscape development. The studies show that encouraging OA does not necessarily solve the food insecurity issues but it is part of the solution because it leads to improvement in accessibility to food and productivity of local food systems. Practicing OA requires training, intensive knowledge and continues access to extension service and information. There is also the need for more research and development by MoFA to improve the adoption of the OA technology by farmers. 


\section{ACKNOWLEDGEMENTS}

The authors wish to thank all the farmers who participated in this research.

\section{REFERENCES}

Ackerman, K., M. Conard, P. Culligan, R. Plunz, M.-P. Sutto and L. Whittinghill. 2014. Sustainable food systems for future cities: The potential of urban agriculture. The economic and social review, 45: 189-206-189-206.

Armar-Klemesu, M. 2000. Urban agriculture and food security, nutrition and health. Growing cities, growing food. Urban agriculture on the policy agenda: 99-118.

Ashely, R., A. Bishop, J. Dennis, J. French, P. Gardam, L. Butler, V. Trebilco, D. O'Donnell, G. Heazlewood and P. Simmul. 2007. Intensive organic vegetable production: integrated development.

Badami, M. G. and N. Ramankutty. 2015. Urban agriculture and food security: A critique based on an assessment of urban land constraints. Global Food Security, 4: 8-15.

Best, H. 2010. Environmental Concern and the Adoption of Organic Agriculture. Society \& Natural Resources, 23: 451-68.

Cabral, P. G. C., E. Maciel-Zambolim, S. A. S. Oliveira, E. T. Caixeta and L. Zambolim. 2015. Genetic diversity and structure ofHemileia vastatrixpopulations onCoffeaspp. Plant Pathology, 65: 196-204.

Dennery, P. 1996. Urban food producers' decisionmaking: a case study of Kibera, City of Nairobi, Kenya. African Urban Quarterly, 11: 189-200.

Drechsel, P., S. Graefe and M. Fink. 2007. Rural-urban food, nutrient and virtual water flows in selected West African cities IWMI.

Drechsel, P. and B. Keraita. 2014. Irrigated urban vegetable production in Ghana: characteristics, benefits and risk mitigationInternational Water Management Institute (IWMI).

Duží, B., A. Tóth, M. Bihuňová and R. Stojanov. 2014. Challenges of urban agriculture: highlights on the Czech and Slovak Republic specifics. Current Challenges of Central Europe: Society and Environment: 82-107.

Eigenbrod, C. and N. Gruda. 2014. Urban vegetable for food security in cities. A review. Agronomy for Sustainable Development, 35: 483-98.

FA0. 2006. The State of Food Insecurity in the World.
Online

available

at

<http://www.fao.org/docrep/009/a0750e/a0750 e00.hhtm> [Accessed 8 June 2020].

FAO/WHO. 2005. The Codex Alimentarius Commission and the FAO/WHO Food Standards. Programme. Guidelines for the Production, Processing, Marketing, and Labelling of Organically Produced Foods.

Freeman, D. B. 1991. City of farmers: Informal urban agriculture in the open spaces of Nairobi, Kenya McGill-Queen's Press-MQUP.

Golden, H. E. and N. Hoghooghi. 2017. Green infrastructure and its catchment-scale effects: an emerging science. Wiley Interdisciplinary Reviews: Water, 5: e1254.

Gonzales, N. M. 1999. Urban Agriculture in the City of Havana. Delivered at international workshop Growing Cities Growing Food (DSE/GTZ/SIDA/CTA/ACPA). La Habana, German Foundation for International Development (DSE).

Gonzalez, M., K. S. B. Miglioranza, J. E. Aizpún de Moreno and V. J. Moreno. 2005. Evaluation of conventionally and organically produced vegetables for high lipophilic organochlorine pesticide (OCP) residues. Food and Chemical Toxicology, 43: 261-69.

Gumbo, D. J. and T. W. Ndiripo. 1996. Open space cultivation in Zimbabwe: A case study of Greater Harare, Zimbabwe. African Urban Quarterly, 11: 210-16

Kristiansen, P. E. 2003. Sustainable weed management in organic herb and vegetable production, University of New England.

Lee-Smith, D., M., Manundu, D., Lamba, P., Gathuru K. . 1957. (1957). Urban Food Production and The Cooking Fuel Situation in Urban Kenya - National Report: Results of 1985 National Survey. . Mazingira Institute, Nairobi.

Mader, P. 2002. Soil Fertility and Biodiversity in Organic Farming. Science, 296: 1694-97.

Mamuya, W. B. 2011. Assessing the impacts of organic farming on domestic and exporting smallholder farming households in Tanzania: a comparative analysis Bangor University (United Kingdom).

Mandel, L. 2013. Eat up: The inside scoop on rooftop agriculture New Society Publishers.

Maxwell, D., C. Levin and J. Csete. 1998. Does urban agriculture help prevent malnutrition? Evidence 
from Kampala. Food Policy, 23: 411-24.

Mbiba, B. 1994. Institutional responses to uncontrolled urban cultivation in Harare: prohibitive or accommodative? Environment and Urbanization, 6: 188-202.

McEldowney, J. 2017. Urban agriculture in Europe. Patterns, challenges and policies. Depth Analysis.

Ministry of Food and Agriculture. 2007. Food and Agriculture Sector Development Policy Accra: Ghana.

Murray, S. 1997. Urban and Peri-Urban Forestry in Quito, Ecuador: A Case Study. Forestry Department, Food and Agriculture Organization, Rome.

Piorr, A., I. Zasada, A. Doernberg, F. Zoll and W. Ramme. 2018. Research for AGRI Committee-Urban and Peri-urban Agriculture in the EU European Parliament.

Poulsen, M. N., P. R. McNab, M. L. Clayton and R. A. Neff. 2015. A systematic review of urban agriculture and food security impacts in low-income countries. Food Policy, 55: 131-46.

Ravallion, M., S. Chen and P. Sangraula. 2007. New evidence on the urbanization of global poverty. Population and development review, 33: 667-701.

Regis, M. D. 1999. Horticultura urbana en Haiti. Taller de evaluacion." Presented at IDRC Cities Feeding People.

Renting, H., C. Naneix, M. Dubbeling and J. Cai. 2013. Innovative experiences with multifunctional (periurban agriculture in city regions in the global South). SUPURBFOOD deliverable, 3 .
Samson, R., T. F. Ningal, A. Tiwary, R. Grote, S. Fares, H. Saaroni, J. A. Hiemstra, M. Zhiyanski, U. Vilhar, P. Cariñanos, L. Järvi, A. Przybysz, M. Moretti and N. Zürcher. 2017. Species-Specific Information for Enhancing Ecosystem Services Future City. Springer International Publishing. pp. 111-44.

Santo, R., Palmer, A. and Brent, K., . 2016. Vacant Lots to Vibrant Plots: A Review of the Benefits and Limitations of Urban Agriculture. Baltimore.

Simon-Rojo, M., X. Recanes, S. Cllau, B. Duzi, S. Eiter, V. Hernández-Jiménez, P. Kettle, R. Laviscio, F. Lohrberg and D. Pickard. 2016. From urban food gardening to urban farming.

Smukler, S. M., L. E. Jackson, L. Murphree, R. Yokota, S. T. Koike and R. F. Smith. 2008. Transition to largescale organic vegetable production in the Salinas Valley, California. Agriculture, ecosystems \& environment, 126: 168-88.

UN Habitat. 2012. Urban Patterns for A Green Economy: Working with Nature. UN Habitat, Nairobi. [Online] Available at: <http://mirror.unhabitat.org/pmss/listltemDetail s.aspx?publicationID=3341.> [Accessed 17 June 2020].

UNEP-UNCTAD. 2008. Organic Agriculture and Food Security in Africa; United Nations: New York, NY, USA.

Willer, H. and J. Lernoud. 2019. The world of organic agriculture. Statistics and emerging trends 2019 Research Institute of Organic Agriculture FiBL and IFOAM Organics International.

Publisher's note: EScience Press remains neutral with regard to jurisdictional claims in published maps and institutional affiliations.

Open Access This article is licensed under a Creative Commons Attribution 4.0 International License, which permits use, sharing, adaptation, distribution and reproduction in any medium or format, as long as you give appropriate credit to the original author(s) and the source, provide a link to the Creative Commons license and indicate if changes were made. The images or other third-party material in this article are included in the article's Creative Commons license, unless indicated otherwise in a credit line to the material. If material is not included in the article's Creative Commons license and your intended use is not permitted by statutory regulation or exceeds the permitted use, you will need to obtain permission directly from the copyright holder. To view a copy of this license, visit http://creativecommons.org/licenses/by/4.0/. 